\title{
O sistema imunológico e a autoimunidade
}

\section{Janaína dos Santos Ferreira}

Graduada em Ciências Biológicas, Centro de Ensino Superior de Juiz de Fora (CES/JF)

E-mail: janainasntsf@gmail.com

\section{Harleson Lopes de Mesquita}

Doutorando em Saúde Brasileira pela Universidade Federal de Juiz de Fora (UFJF), Minas Gerais, Brasil

Docente na Faculdade de Ciências Médicas e da Saúde de Juiz de Fora - SUPREMA (PCMS/JF), Universidade Presidente Antônio Carlos (UNIPAC/JF) e no Centro Universitário de Barra Mansa (UBM)

E-mail:harlefar@hotmail.com

\section{Danielle Maria de Oliveira Aragão}

Universidade Federal de Juiz de Fora (UFJF), Minas Gerais, Brasil

Doutora em Ciências Biológicas na Universidade Federal de Juiz de Fora (UFJF)

Docente na Universidade Federal de Juiz de Fora (UFJF)

E-mail: danifarma21@yahoo.com.br

\section{Carina de Almeida Bastos}

Faculdade do Sudeste Mineiro (FACSUM-JF), Minas Gerais, Brasil

Doutora EM Química pela Universidade Federal de Juiz de Fora (UFJF)

Docente na Faculdade do Sudeste Mineiro (FACSUM-JF

E-mail: cbastos2203@yahoo.com.br 


\section{Resumo}

O sistema imune é responsável pela proteção do organismo por meio de mecanismos de defesa, possuindo uma grande importância na proteção contra agentes patogênicos e infecciosos. Alguns distúrbios e falhas podem ocorrer no processo de defesa, seja por células apresentadoras de antígenos, anticorpos ou por falhas em outros mecanismos. Uma das principais consequências dessas falhas é o desenvolvimento de doenças autoimunes que podem agravar-se ao longo do tempo. Assim, compreender sobre as funções e mecanismos de produção de anticorpos capazes de desencadear respostas autoimunes é de grande relevância quando o próprio organismo gera consequências negativas a determinados órgãos e/ou tecidos. Atualmente, há muitos estudos relacionados à autoimunidade direcionados somente para um tipo de doença. Por se tratar de um sistema complexo, este trabalho proporcionou um entendimento sobre o funcionamento do sistema imunológico e a atuação de suas células, além de informar os principais motivos que ocasionam doenças autoimunes.

Palavras-chave: Estresse oxidativo. Homeostase. Tolerância.

\section{Abstract}

The immune system is responsible for protecting the organism through defense mechanisms, having a great importance in the protection against pathogens and infectious agents. Some disorders and failures may occur in the defense process, either by antigen presenting cells, antibodies or by failures in other mechanisms. One of the main consequences of these failures is the development of autoimmune diseases that can worsen over time. Thus, understanding the functions and mechanisms of antibody production capable of triggering autoimmune responses is of great relevance when the organism itself has negative consequences for certain organs and / or tissues. There are many studies of autoimmunity related to only one type of disease. Because it is a complex system, this work has provided an understanding about the functioning of the immune system and the performance of its cells, as well as informing the main reasons that cause autoimmune diseases.

Keywords: Oxidative stress. Homeostasis. Tolerance. 


\section{Introdução}

A imunidade pode ser caracterizada como um conjunto de mecanismos que o corpo humano possui de defesa e resistência contra agentes patogênicos e tecidos danificados. No organismo, há um conjunto de células, tecidos e moléculas que intervêm e auxiliam nessa resistência, chamado de Sistema Imune (S.I.). Uma resposta imune pode ser desencadeada quando há uma estimulação por uma reação regulada desse sistema (ABBAS, et al. 2015).

O S.I. tem como principal função fisiológica prevenir e eliminar o que for prejudicial ao organismo, como agentes infecciosos e patogênicos. Substâncias estranhas, mesmo não sendo infecciosas, também podem estimular respostas imunes. Logo, a resposta imune pode ser mais bem descrita como uma reação a macromoléculas tais como proteínas e polissacarídeos presentes em microrganismos e agentes químicos caracterizados como estranhos, independente da reação fisiológica ou patológica de tal comportamento. Em alguns casos, moléculas produzidas pelo próprio organismo podem ser reconhecidas como estranhas e, dessa forma, provocar uma resposta imune, resultando em doenças denominadas como autoimunes (ABBAS, et al. 2015).

Para que o S. I. cumpra seu papel de defesa, é importante que ele diferencie as moléculas próprias das não próprias do organismo (NOGUEIRA, et al. 2010). Paul Ehrlich foi o primeiro autor a apresentar o conceito de autoimunidade, denominando-a de horror autotoxicus. Tempos depois foram feitos mais estudos para compreender melhor como a autoimunidade ocorre (MURPHY, 2014).

$\mathrm{Na}$ literatura, há muitos relatos relacionados ao S.I., como suas atuações no organismo, o que ocorre quando há um desequilíbrio nesse sistema ou suas ações relacionadas a agentes infecciosos. Com relação às doenças autoimunes, são encontrados muitos relatos descrevendo uma única doença, mas não expondo um conjunto que correlacione o sistema como um todo e suas ações e consequências em relação à autoimunidade no geral.

Diante do que foi descrito, o objetivo deste trabalho foi realizar uma revisão de literatura com a finalidade de unir informações necessárias para um entendimento sobre o que é o sistema imunológico, e partir disso, aprender como as estruturas desse sistema atuam em relação à presença de doenças autoimunes. Além disso, teve como objetivo, 
também, demonstrar condições que são favoráveis e/ou responsáveis por proporcionar um desenvolvimento prejudicial de autoimunidade no organismo.

\section{Metodologia}

Este trabalho foi desenvolvido e constituído por meio de um minucioso levantamento bibliográfico nos principais bancos de dados de estudos como: Oxford Academic, Scielo, PubMed, SageJournals, Periódicos Capes, revistas científicas, literatura biológica entre outros. Para ajudar nas buscas, foram utilizadas palavras-chave como: imunidade, autoimunidade, tolerância, linfócitos, doenças autoimunes, entre outras. A pesquisa bibliográfica foi separada em duas etapas, sendo a primeira a identificação do aspecto a ser pesquisado e do tipo de documento que se deseja revisar e a segunda do fichamento do material pesquisado.

\section{Fundamentação Teórica}

\section{Caracterizações do sistema imune}

As células do S.I. procedem de duas linhagens: células da linhagem mieloide e as células da linhagem linfoide (ABBAS, LICHTMAN, POBER, 2003). As células da linhagem mieloide diferenciam-se em granulócitos, fagócitos mononucleares, células dendríticas e mastócitos do S.I. e vão para a corrente sanguínea. A partir da linhagem dos granulócitos são originados os neutrófilos (principais responsáveis pela resposta inata), eosinófilos, basófilos, mastócitos e as plaquetas. Já as células linfoides dão origem aos linfócitos $\mathrm{B}$ e $\mathrm{T}$ e as células NK (natural killer) (VERRASTRO, LORENZI, WENDEL NETO, 2010). Essa organização pode ser observada na figura 1.

Figura 1: Demonstração da origem das células do Sistema Imune. 


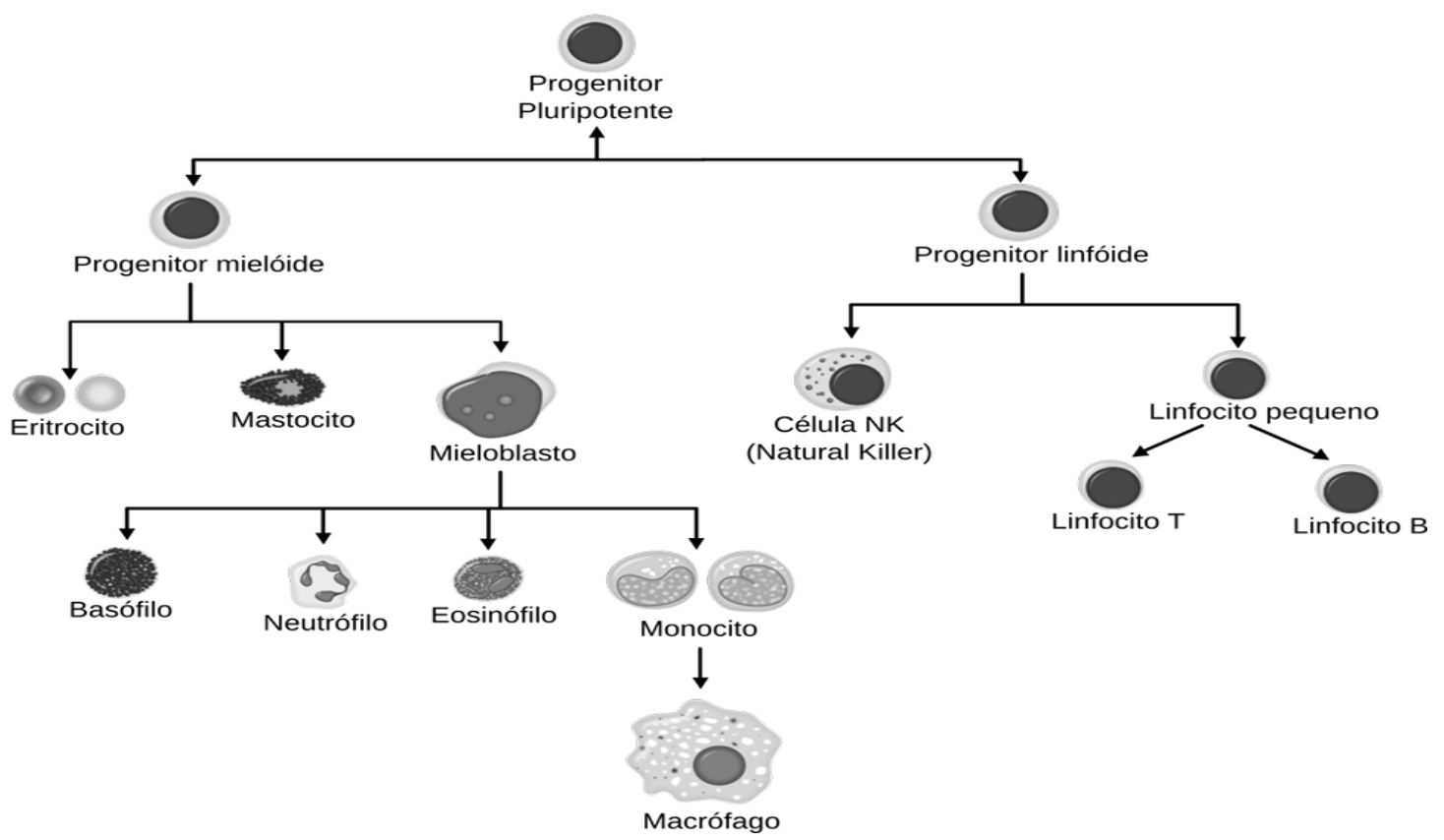

Fonte: Os autores.

A resposta imune inata é caracterizada pela resposta rápida com a ação de um conjunto células, mas com poucos estímulos. Esse tipo de resposta é formado por barreiras físicas, químicas e biológicas, e presente no indivíduo desde o seu nascimento sem que haja necessidade de um contato precedente com agentes agressores para que seja desencadeada a resposta (CRUVINEL et al., 2010).

Diferentemente, a resposta imune adaptativa ou adquirida necessita de um estímulo de antígenos para que ocorra a ativação de células especializadas. A resposta adaptativa possui especificidade de reconhecimento, memória e melhoramento de resposta. As células apresentadoras de antígenos (APCs) possuem um papel fundamental nesse tipo de resposta, visto que elas apresentam os antígenos associados a moléculas do complexo de histocompatibilidade (MHC) principal para as células dos linfócitos T (CRUVINEL et al., 2010).

Os linfócitos $\mathrm{T}$ têm o seu amadurecimento feito no timo, são responsáveis pela imunidade mediada por células, possuindo função de eliminar organismos como vírus e bactérias intracelulares com o propósito de exterminar a infecção no corpo (ABBAS, 2012). Os linfócitos T são divididos em diferentes tipos de acordo com sua função. Já os linfócitos B são originados das células indiferenciadas produzidas na medula óssea, responsáveis pela produção de anticorpos na resposta imune adaptativa (VERRASTRO, LORENZI, WENDEL NETO, 2010). 


\section{Tolerância}

A tolerância pode ser classificada como a falta de resposta imunológica ativa a um determinado antígeno na ausência de imunossupressão contínua. Esse processo pode ocorrer por uma mediação entre os linfócitos T e B (BUENO; PACHECO-SILVA, 1999).

A autotolerância possui a capacidade de diferenciação no sistema imunológico do que é próprio (self) do organismo e do que não é próprio (non-self). Nas doenças autoimunes tanto órgãos-específicas quanto sistêmicas é possível constatar que há uma perda da capacidade do sistema imunológico em realizar essa diferenciação de self e non-self. Essa autotolerância é mantida tanto nas células T quanto B por meio de mecanismos centrais e periféricos com processos de anergia $^{1}$ e deleção ${ }^{2}$ (SOUZA et al., 2010), como demonstrado na figura 2.

Figura 2: Mecanismos de tolerância.

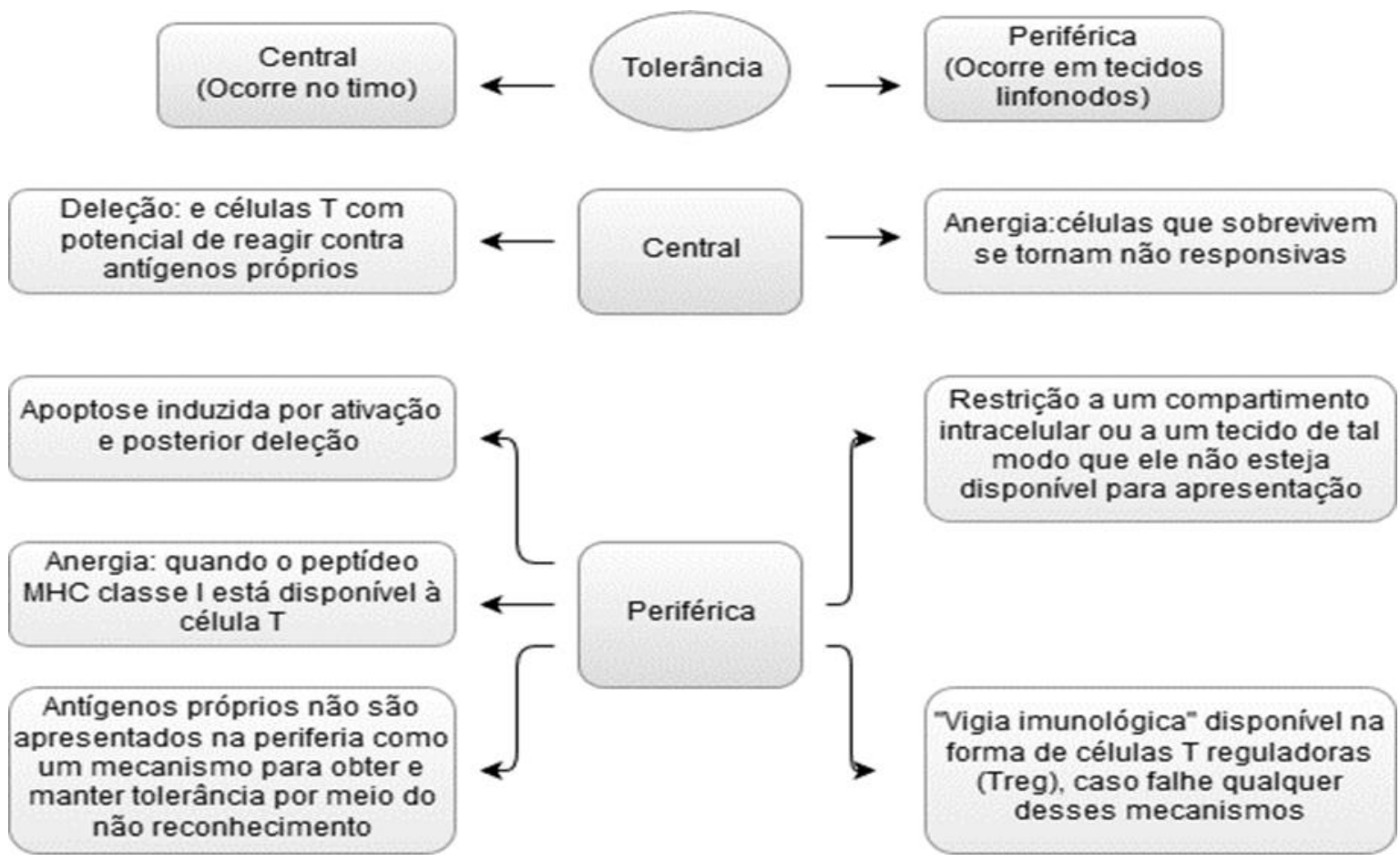

Fonte: Os autores.

\footnotetext{
${ }^{1}$ Inativação funcional dos linfócitos pela não expressão de moléculas coestimuladoras em suas membranas.

${ }^{2}$ Mutação caracterizada pela remoção de um segmento de um cromossomo.
} 
A autotolerância diz respeito ao reconhecimento e à eliminação de antígenos que não são próprios do organismo. Contudo, distúrbios desse sistema com reações exageradas contra próprios antígenos ocasionam o desenvolvimento das doenças autoimunes (PINTO; BANI; PAIVA, 2015).

\section{Células Tregs e a tolerância imunológica}

As células $\mathrm{T}$ reguladoras ou células Treg são originadas do timo, apresentando funções supressoras. Dessa forma, foi identificado que o aparecimento de doenças autoimunes estaria ligado ao desaparecimento ou deficiência dessas células (SCHMETTERER; NEUNKIRCHNER; PICKL, 2012). Assim, entende-se que as células Treg podem estabelecer relações fundamentais na prevenção e controle do desenvolvimento das patologias autoimunes, além de também possuírem função na regulação da resposta imunológica contra determinadas doenças alérgicas (AFZALI et al., 2007).

A tolerância imunológica é, de fato, um processo que possibilita, desde o desenvolvimento mais antecipado até o decorrer de toda a vida, uma resposta controlada a certos autoantígenos que participam no processo de desencadeamento de autoimunidade. Mecanismos centrais como a deleção clonal ${ }^{3}$, por exemplo, fazem com que as células autorreativas sejam eliminadas. Entretanto, algumas células escapam e não são exterminadas, migrando, assim, até a periferia. Então, o processo de tolerância periférica, que tem as células Treg como um dos seus mecanismos mais conhecidos no seu desempenho, tem como função inativar essas células que migraram, fazendo com que ocorra uma prevenção ao desenvolvimento das doenças autoimunes. Devido a esses mecanismos, o número de pessoas com patologias autoimunes é menor (LA CAVA, 2008).

Essas células Treg têm a capacidade de impulsionar a anulação das células $\mathrm{T}$ efetoras na presença de antígenos normais ou autoantígenos que em grande escala provocam a autoimunidade (LA CAVA, 2008).

Autoimunidade

${ }^{3}$ Remoção por morte celular, de linfócitos imaturos que interagem com antígenos durante a maturação. 
Normalmente o sistema imune tem o papel de defender o organismo de agentes patogênicos. Contudo, quando ocorre uma falha no sistema e ele reage contra suas próprias células, tecidos ou órgãos, acarretando em problemas no seu funcionamento ou até mesmo levando a sua própria destruição, denominam-se esses fatores de doença autoimune (PINTO, BANI, PAIVA 2015).

Nas doenças autoimunes, as próprias células do S.I. causam danos ao organismo, podendo envolver tanto anticorpos quanto células $\mathrm{T}$ efetoras. A autoimunidade pode ocorrer devido a mecanismos como a perda do controle da resposta imunológica e falha de autotolerância. Quando um antígeno induz a uma tolerância no organismo, isso se refere à reatividade imunológica específica a determinado antígeno (HUNT, D.M., 2015).

$\mathrm{O}$ mais importante quando se trata de tolerância é o fato de não haver reatividade a antígenos do próprio organismo. Geralmente o S.I não reage com uma resposta imune forte o bastante contra os nossos próprios antígenos e esse reconhecimento é chamado de autotolerância. Mas, quando o S.I. reconhece esse antígeno e provoca fortemente uma resposta contra ele, tem-se como resultado o desenvolvimento de uma doença autoimune (HUNT, D.M., 2015).

Existem diversos fatores que podem causar a perda da autotolerância, que podem ser caracterizados como intrínsecos ou extrínsecos. Nos fatores intrínsecos os genes estão relacionados com a codificação das moléculas de MHC responsáveis pela imunidade inata e o sistema complemento, por exemplo, e também pela imunidade adaptativa, tendo os linfócitos, fatores hormonais e atividades regulatórias como exemplo. Já quanto aos fatores extrínsecos, podem ser citados exemplos de infecções tanto bacterianas quanto as virais, ocasionadas por fatores ambientais, exposição a determinados tipos de agentes físico-químicos e drogas, dentre outros (SOUZA, et al 2009). Na figura 3 é possível observar de forma simplificada como atuam os fatores genéticos e ambientais. 
Figura 3: Fatores para o desenvolvimento de doenças autoimunes.

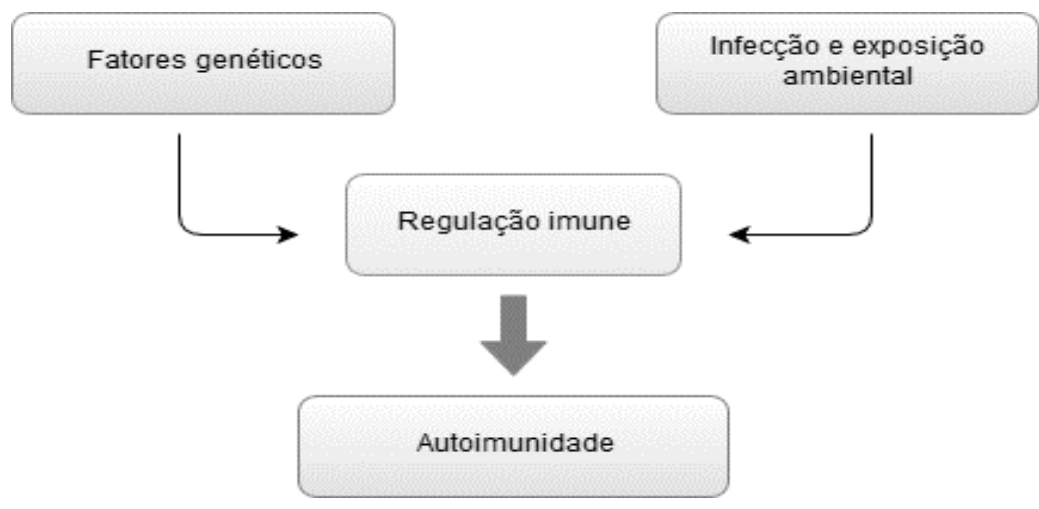

Fonte: Os autores.

Uma doença caracterizada como autoimune ou por imunodeficiência existe devido a uma perda de função das células $\mathrm{T}$ ou $\mathrm{B}$. Grandes partes das doenças autoimunes são provenientes de fatores multigênicos, devido a genes que possuem susceptibilidade múltipla e que trabalham em conjunto, sendo capazes de produzir um fenótipo anormal. Porém, em um contexto geral, as mutações gênicas também são capazes de ocorrer em pessoas normais, compatíveis com a função imunológica normal. Somente quando estão com outros genes suscetíveis é que irão contribuir e favorecer para a autoimunidade. A apoptose celular é um processo que caracteriza a morte celular de forma programada e quando há um problema ou desregulação nesse mecanismo, isso pode gerar autoantígenos que serão responsáveis pela autoimunidade (HEEMANN et al, 2014).

Como mecanismo de autoimunidade existem também os autoanticorpos (principalmente $\operatorname{IgG}$ ) que fazem ligação com os próprios antígenos. Eles podem ser patogênicos como, por exemplo, no caso da doença de Graves (DG), em que os autoanticorpos são conduzidos em oposição ao receptor de TSH, um hormônio estimulante da tireoide, e, dessa forma, impulsionam a produção de mais hormônios tireoidianos, desenvolvendo uma patologia, como o hipertireoidismo (SPERLING, 2015). Entretanto, os autoanticorpos têm como propósito auxiliar como marcadores sorológicos para a identificação da autoimunidade, como no caso da diabetes tipo 1, por exemplo (SPERLING, 2015).

Doenças autoimunes 
As doenças autoimunes possuem normalmente uma classificação referente ao órgão ou tecido que é atingido. Podendo ser do tipo órgão-específico, onde o S.I. impõe uma resposta direcionada contra os antígenos associados com o órgão-alvo que está sendo prejudicado ou pelo tipo de não especificidade, em que há um direcionamento condicionado a um determinado antígeno não associado com o órgãoalvo (GHAFFAR, 2017).

As doenças autoimunes possuem etiologia complexa. Há teorias que indicam a possibilidade de que células $\mathrm{T}$ não tenham tido contato e reconhecido de forma adequada determinados antígenos próprios e, por serem de desenvolvimento tardio ou por estarem em órgãos específicos, como por exemplo, na tireóide, há ausência de células $\mathrm{T}$ regulatórias (Tregs). A maioria das autoimunidades apresenta traços poligênicos complexos em que indivíduos herdam polimorfismos genéticos múltiplos, contribuindo ainda mais para a susceptibilidade à doença (ABBAS; LICHTMAN; PILLAI, 2012). Na tabela 1, é possível observar alguns tipos dessas doenças e o mecanismo resultante que faz com que cada uma seja desencadeada.

Tabela 1: Algumas doenças autoimunes com seus mecanismos e consequências.

\begin{tabular}{|c|c|c|}
\hline Doenças & Mecanismo resultante & Consequência \\
\hline Doença de Graves (DG) & $\begin{array}{c}\text { Autoanticorpos contra o receptor } \\
\text { do hormônio estimulante da } \\
\text { tireóide }\end{array}$ & $\begin{array}{c}\text { Hipertireoidismo: } \\
\text { superprodução de hormônios } \\
\text { da tireóide }\end{array}$ \\
\hline Artrite Reumatoide (AR) & $\begin{array}{c}\text { Células T atacam antígenos da } \\
\text { sinóvia da articulação }\end{array}$ & $\begin{array}{l}\text { Inflamação e destruição das } \\
\text { articulações, ocasionando a } \\
\text { artrite }\end{array}$ \\
\hline Tireoidite de Hashimoto & $\begin{array}{c}\text { Autoanticorpos e células } \mathrm{T} \\
\text { autorreativas contra antígenos da } \\
\text { tireóide }\end{array}$ & $\begin{array}{c}\text { Destruição de tecidos da } \\
\text { tireóide ocasionando o } \\
\text { hipotireoidismo: subprodução } \\
\text { de hormônios da tireóide }\end{array}$ \\
\hline
\end{tabular}




\section{Células T autorreativas contra}

Diabetes mellitus tipo I antígenos das células pancreáticas presentes nas ilhotas
Destruição das células $\beta$

pancreáticas levando a nãoprodução de insulina

\begin{tabular}{|c|c|c|}
\hline Esclerose múltipla (EM) & $\begin{array}{c}\text { Células T autorreativas contra } \\
\text { antígenos do cérebro }\end{array}$ & $\begin{array}{l}\text { Formação de placas } \\
\text { escleróticas no cérebro com } \\
\text { destruição das bainhas de } \\
\text { mielina que envolvem os } \\
\text { axônios na célula nervosa, } \\
\text { ocasionando a fraqueza } \\
\text { muscular e outros sintomas }\end{array}$ \\
\hline $\begin{array}{l}\text { Lúpus eritematoso } \\
\text { sistêmico (LES) }\end{array}$ & $\begin{array}{c}\text { Autoanticorpos e células T } \\
\text { autorreativas contra DNA, } \\
\text { cromatina, proteínas e antígenos de } \\
\text { ribonucleoproteínas }\end{array}$ & $\begin{array}{c}\text { Glomerulonefrite, vasculite, } \\
\text { eritema }\end{array}$ \\
\hline
\end{tabular}

Fonte: Os autores.

A autoimunidade pode ser resultado de combinações de predisposição genética com a quebra dos mecanismos de tolerância e com fatores ambientais (MURPHY, TRAVERS, WALPORT 2010). Inúmeros fatores sugerem que genes que estão associados ao MHC podem estar diretamente relacionados na regulação imune e na patogenia destas doenças autoimunes (RÊGO, 2009). A patogenia das autoimunidades é determinada pela ausência ou perda da tolerância imunológica e pela reatividade a antígenos. É o caso das doenças tireoidianas, em que ocorre uma infiltração na glândula por linfócitos T e B reativos e, consequentemente, há uma produção de autoanticorpos. Assim, é possível ser desencadeado um hipertireoidismo na DG e um hipotireoidismo na tireoidite de Hashimoto (SGARBI; MACIEL, 2008).

Alterações que diminuem a ativação de células B autorreativas, em muitos casos, provocam a produção de autoanticorpos múltiplos, como no caso dos anticorpos antinucleares e anti-DNA, no LES. Outro caso são as alterações na função de regulação das células $\mathrm{T}$ e na produção de citocinas, que podem ocasionar diversas vezes uma 
doença por inflamação intestinal, podendo refletir na ativação dessas células, de modo que haja uma resposta exacerbada com intuito de destruir a microbiota residente (DAVIDSON; DIAMOND, 2001). Observa-se também uma expressão anormal de MicroRNAs $^{4}$ (miRNAs) em várias condições patológicas, inclusive em doenças autoimunes, visto que polimorfismos em genes que codificam miRNAs são capazes de alterar a expressão gênica e conferir maior probabilidade a doenças (MARTINS et al., 2015).

\section{Vitamina D}

A vitamina $\mathrm{D}$ além de poder ser consumida através de alimentos ou adquirida por suplementações, também pode ser sintetizada de forma cutânea por meio de contato com o sol. Essa vitamina contribui no desenvolvimento e manutenção do tecido ósseo e também influencia no metabolismo do fósforo e cálcio no corpo (SOUSA, 2016).

Ainda não se entende perfeitamente o modo de ação dessa vitamina pelo seu receptor de vitamina D nuclear (RVD) e sua contribuição para diversos transtornos. No entanto, é possível saber que há um grande papel para a regulação e homeostase do S.I. no que diz respeito à autotolerância e à autoimunidade, que obtém um forte impacto da vitamina D sobre os nossos genes (RAMAGOPALAN et al., 2010). Por isso, quando um organismo se encontra com deficiência ou insuficiência de vitamina $D$, há uma chance maior de ser desencadeado algum tipo de doença, pelo fato da grande importância que essa vitamina possui (SOUSA, 2016).

Estudos apontam a relação da carência ou da falta de vitamina $\mathrm{D}$ com inúmeras doenças autoimunes, pois ela atua fortemente como um hormônio que regula a proliferação, maturação e a apoptose celular, influenciando, dessa forma, no aparecimento e desenvolvimento de doenças. (MARQUES, et al 2010).

A deficiência sérica de vitamina $\mathrm{D}$ é um fator muito importante e de risco para o aparecimento de diversas doenças, como, por exemplo, as doenças reumáticas autoimunes, sendo que essa vitamina controla e regula a imunidade inata e adaptativa, elevando o potencial da imunidade inata, porém reduzindo a imunidade adaptativa na apresentação de antígenos e principalmente nas atividades de células T e B. Sua deficiência proporciona um aumento na produção de autoanticorpos pelas células B e

\footnotetext{
${ }^{4}$ Pequenos RNAs capazes de regular a expressão de genes em nível pós-transcricional através da degradação ou repressão da tradução de moléculas-alvo de RNA mensageiro.
} 
consequentemente problemas na pele de pessoas com doenças reumáticas autoimunes. (CUTOLO, PIZZORNI, SULLI 2011).

Segundo as pesquisas de Ramagopalan et al. (2010), na vitamina D existem aproximadamente 2.776 sítios de ligação que atuam sobre o genoma humano e parte deles está associada com doenças autoimunes, como a diabetes tipo 1. A vitamina D é encontrada em grande concentração nas células imunológicas imaturas, como as localizadas no timo, e nos linfócitos CD8 maduros, autonomamente do estado de ativação em que se encontra. É possível observar as atividades desempenhadas no organismo com efeitos no sistema imunológico pela vitamina D. Por essa razão, a vitamina $\mathrm{D}$ e seus componentes, além de prevenirem que doenças autoimunes sejam desencadeadas, podem também ser utilizados em tratamentos referentes a elas (MARQUES, et al. 2010).

\section{Estresse oxidativo e autoimunidade}

O estresse oxidativo acontece devido a uma instabilidade ou desequilíbrio entre a geração de compostos oxidantes junto da ação dos sistemas de defesa antioxidantes. O processo de radicais livres e/ou espécies reativas não radicais é resultante do metabolismo de oxigênio (BARBOSA et al., 2010). A definição desse desequilíbrio no estresse oxidativo ocorre por meio de níveis de compostos próoxidantes e antioxidantes. Essa condição pró-oxidante relaciona-se a diversas doenças cardiovasculares, neurodegenerativas, cânceres e, inclusive, doenças autoimunes (VELLOSA et al., 2013).

O estresse oxidativo celular está diretamente ligado com o desenvolvimento de diversas características clínicas observadas em algumas doenças. Entre às patologias que envolvem o processo do estresse oxidativo, destaca-se o Lúpus Eritematoso Sistêmico (LES) em relação à autoimunidade (BARREIRA et al., 2015).

O LES está associado a predisposições genéticas e interferências ambientais que ocasionam um desequilíbrio no S.I. e resultam em produções de autoanticorpos, além da formação de imunocomplexos. Por sua vez, esses autoanticorpos estão localizados em inúmeros tecidos do organismo e, assim, são os mediadores pela ativação de células teciduais e do S.I., causando um efeito cascata e liberando mediadores inflamatórios (BARREIRA et al., 2015). Considera-se que o estresse oxidativo formado devido ao desequilíbrio em relação à formação e à remoção de substâncias reativas, por meio de 
grande ativação celular, desenvolve um importante papel nas manifestações clínicas que são observadas nessa doença. Em estudos feitos sobre o LES, notou-se que o estresse oxidativo tem sua iniciação nas células TCD4 e TCD8 e assim, gradativamente, afeta células que implicam na resposta imune e na fisiopatogenia dessa doença autoimune (BARREIRA et al., 2015).

A grande produção de espécies reativas de oxigênio ocasiona danos em lipídeos, proteínas, membranas e ácidos nucléicos, servindo também como um fator relevante na sinalização intracelular que expande as respostas inflamatórias. Devido a isso, é possível relacionar as espécies reativas de oxigênio em patogêneses crônicas inflamatórias como a AR (FILIPPIN et al., 2008).

A agregação entre o excesso de espécies reativas de oxigênio e as doenças autoimunes está relacionada com o prejuízo no mecanismo celular. Observa-se que os níveis de oxidantes e antioxidantes representam um problema na homeostasia, por esse motivo relaciona-se o estresse oxidativo com diferentes tipos de doenças (VELLOSA et al., 2013). Espécies reativas de oxigênio podem ser produzidas em processos inflamatórios, por meio de mecanismos de defesa contra agentes patogênicos, doenças crônicas e inclusive doenças autoimunes. E quando há uma produção exacerbada, há uma contribuição para o estresse oxidativo (MEDEIROS, 2014).

Tratamentos das doenças autoimunes no geral

Ainda não há um tratamento que seja a cura total para as doenças autoimunes em si, mas sim uma abordagem terapêutica à base de drogas que consistem em manter um controle dos hormônios e células e em diminuir os sintomas provocados por determinada doença autoimune. Além disso, por se tratarem de doenças que não possuem uma cura definitiva, é necessário que haja sempre um controle médico (NEVES, et al., 2008). Com o desenvolvimento crescente da nanotecnologia, têm-se proporcionado formas de tratamentos em busca de atenuar doenças, como, por exemplo, a EM (COSTA et al., 2017).

Há uma busca por tratamentos mais eficazes, que visam um resultado mais satisfatório em relação a doença e o bem-estar do paciente. No caso das doenças autoimunes tireoidianas podem ser usadas opções terapêuticas como a utilização de drogas anti-tireoidianas (DAT), cirurgia e iodo radioativo, principalmente no caso da DG (OLIVEIRA; MALDONADO, 2014). 
Utilização de corticoides

Inúmeros remédios imunossupressores têm sido utilizados a fim de controlar a progressão de doenças autoimunes. Porém, para ter o efeito desejado de controle, é necessário que algumas drogas sejam administradas de forma contínua, para bloquear a resposta imune indesejada. Para isso, tem-se buscado maneiras de imunossupressão que atinjam diretamente o sítio de ativação imune, para bloquear estas respostas (BUENO, SILVA 1999). Existem vários mecanismos externos que proporcionam o desenvolvimento da autoimunidade, entre eles podem ser citados o uso de drogas, imunossupressores ou corticosteroides e ingestão de iodo. Esses fatores podem levar ao desenvolvimento de uma disfunção tireoidiana no lúpus eritematoso sistêmico (ROBAZZI, ADAN, 2012).

Em relação aos glicocorticoides pode-se dizer que são utilizados em diversos tratamentos contra muitas doenças, ainda que seu uso constante possa causar algum tipo de prejuízo ao organismo. A corticoterapia é um assunto bastante indicado e incontestável em tratamentos como terapia substitutiva em pessoas que não são mais capazes de produzir cortisol normalmente. Entretanto, há uma necessidade de verificar, cuidadosamente, os efeitos benéficos e os efeitos colaterais que o uso dessa droga pode gerar (DAMIANI et al., 2001).

\section{Considerações Finais}

Por meio de revisões bibliográficas foi possível identificar, a partir das informações abordadas no texto, quais os principais motivos que ocasionam distúrbios autoimunes. Dessa forma, pode-se concluir que o sistema imunológico possui inúmeras estruturas com mecanismos de defesa contra agentes patogênicos. Entretanto, podem ocorrer problemas no sistema imune que são capazes de propiciar autoimunidades, como, por exemplo, disfunções, principalmente, nas células T, por meio de falhas no sistema de tolerância que atua para que não haja reatividade a antígenos do próprio organismo. Outro processo do sistema imunológico que pode acionar problemas de autoimunidade é a falha nas células Treg, que têm a capacidade de suprimir as células T autorreativas. Dessa forma, sem essa supressão, podem ocorrer distúrbios que também levam ao aparecimento de doenças autoimunes. Ressaltou-se que esses problemas 
podem estar relacionados tanto com fatores ambientais, como na insuficiência ou deficiência de vitamina $\mathrm{D}$, quanto com a hereditariedade, passando assim de geração em geração em determinados casos.

Foi observado que todas as doenças autoimunes não possuem cura, porém, há tratamentos que são capazes de ajudar no controle e melhora dos sintomas. Além disso, podem ser caracterizadas a partir da região em que ocorrem, sendo em determinada glândula, órgão ou sistema. Outra condição que se observou ser importante foi o fato de serem usados determinados corticosteroides com a finalidade de tratamento de algumas doenças autoimunes. No entanto, com o tempo, esse tratamento pode levar ao aparecimento de outros tipos de autoimunidades.

Então, por meio deste trabalho, fez-se uma conexão entre o sistema imunológico e seus mecanismos principais de defesa, objetivando uma visão do todo e, consequentemente, tornando possível uma melhor compreensão do surgimento das doenças autoimunes. Entende-se que há uma necessidade de mais pesquisas e estudos relacionados ao sistema imunológico e às doenças que se desenvolvem a partir de falhas em seus mecanismos. Além disso, é necessário explorar e investigar sobre tratamentos que sejam mais eficazes nos sintomas sem que ocorram efeitos adversos como o aparecimento de outras doenças.

\section{Referências}

ABBAS, A. K.; LICHTAMAN, A. H.; POBER, J. S. Imunologia Celular e Molecular. 4. ed. Rio de Janeiro: Revinter Ltda, 2003.

ABBAS, A. K.; LITCHMAN, A. H.; PILLAI, S. Imunologia Celular e Molecular. 7. ed. Rio de Janeiro: Elsevier, 2012.

ABBAS, A. K.; LITCHMAN, A. H.; PILLAI, S. Imunologia Celular e Molecular. 8. ed. Rio de Janeiro: Elsevier, 2015.

AFZALI, B. et al. The role of T helper 17 (Th17) and regulatory T cells (Treg) in human organ transplantation and autoimmune disease. Clinical \& Experimental Immunology, London, v. 148, n. 1, p.32-46, 2007. 
BARREIRA, T. G. et al. Estresse oxidativo no lúpus eritematoso sistêmico. Revista Brasileira de Análises Clínicas, Niterói, v. 47, n. 3, p.66-73, 2015.

BUENO, V.; PACHECO-SILVA, A. Tolerância oral: uma nova perspectiva no tratamento de doenças autoimunes. Revista da Associação Médica Brasileira, São Paulo, v. 45 , n. 1, p.79-85, 1999.

COSTA, T. M. de S. et al. Diagnósticos, resultados e intervenções de enfermagem em pacientes com esclerose múltipla. Revista Cubana de Enfermería, [S.1.], v. 33, n. 3, 2017.

CUTOLO M., PIZZORNI C, SULLI A. Vitamin D endocrine system involvement in autoimmune rheumatic diseases. Autoimmun Rev. pag. 84, 2011.

CRUVINEL, W. de M. et al. Sistema imunitário: Parte I. Fundamentos da imunidade inata com ênfase nos mecanismos moleculares e celulares da resposta inflamatória.

Revista Brasileira de Reumatologia, São Paulo, v. 50, n. 4, p.434-447, 2010.

DAMIANI, D. et al. Corticoterapia e suas repercussões: a relação custo-benefício. Revisão e Ensaio, São Paulo, v. 1, p.71-82, 2001.

DAVIDSON, A.; DIAMOND, B. Autoimmune diseases. N Engl J Med, v. 345, n.5, p. $340-350,2001$.

FILIPPIN, L. I. et al. Influência de processos redox na resposta inflamatória da artrite reumatóide. Revista Brasileira de Reumatologia, São Paulo, v. 48, n. 1, p.17-24, 2008.

GHAFFAR, A. Imunologia - Capítulo dezesseis, Tolerância e Autoimunidade. 2017. Imunidade Inata. Disponível em: <www.microbiologybook.org/Portuguese/immunoport-chapter16.htm>. Acesso em: 10 nov. 2017.

HEEMANN, B. F. et al,. Abordagem imunogenética das proteínas apoptóticas na patogênese do lúpus eritematoso sistêmico. Clin Biomed Res, Porto Alegre, p. 252, 2014. 
HUNT D.M. Influenza. In: Microbiology and Immunology. Disponível em: <www.microbiologybook.org/mhunt/flu.htm>. Acesso em: 23 out. 2017.

LA CAVA, A. T-regulatory cells in systemic lupus erythematosus. Lupus, [s.i.], v. 17, n. 5, p.421-425, 2008.

MARQUES, C. D. L. et al. A importância dos níveis de vitamina D nas doenças autoimunes. Revista Brasileira de Reumatologia, São Paulo, v. 50, n. 1, p.67-80, fev. 2010.

MARTINS, E. M. et al., O polimorfismo rs2910164 no gene codificador do microRNA-146 a está associado com risco para o diabetes mellitus tipo 1. Clin Biomed Res, Porto Alegre, p. 108, 2015.

MEDEIROS, M. S. Associação entre metabolismo do ferro e estresse oxidativo em pacientes com doença de Parkinson. 2014. 93 f. Dissertação (Mestrado) - Curso de Pósgraduação em Ciências Médicas, Universidade Federal do Rio Grande do Sul, Porto Alegre, 2014.

MURPHY, K. Imunobiologia de Janeway. 8. ed., Porto Alegre: Artmed, 2014.

MURPHY, K.; TRAVERS P.; WALPORT M. Imunobiologia de Janeway. 7. ed. [s.i.]: Editora Artmed, 2010.

NEVES, C. et al. Doença de Graves. Arquimed, Porto, v. 22, n. 4, p.46-137, 2008.

OLIVEIRA, V.; MALDONADO, R. R. Hipotireoidismo e hipertireoidismo - uma breve revisão sobre as disfunções. Interciência e Sociedade, São Paulo, v. 3, n. 2, p.3644, 2014.

PINTO, M.; BANI, G.; PAIVA, P. Mecanismo de indução de tolerância oral no tratamento de doenças autoimunes. Revista da Uiips, Sul de Minas, v. 3, n. 2, p.1-19, 2015.

RAMAGOPALAN, S. V. et al. A ChIP-seq defined genome-wide map of vitamin D receptor binding: Associations with disease and evolution. Genome Research, Maryland -USA, v. 20, n. 10, p.1352-1360, 24 ago. 2010. 
RÊGO, J. Pesquisa de autoanticorpos contra antígenos intracelulares, em células HEp2, em Goiânia Goiás. 2009. 108 f. Tese (Doutorado) - Curso de Pós-graduação em Ciências da Saúde, Universidade Federal de Goiás, Goiânia, 2009.

ROBAZZI, T. C. M. V.; ADAN, F. F. Ocorrência de doenças autoimunes tireoidianas em pacientes com doenças reumáticas. Revista Brasileira de Reumatologia, São Paulo, v. 52, n. 3, p.423-430, 2012.

SGARBI, J. A.; MACIEL, R. M. B. Patogênese das doenças tiroidianas autoimunes. Arq Bras Endocrinol Metab, São Paulo, v. 53, n. 1, p.5-14, 2008.

SOUSA, S. M. de. A vitamina D e o seu papel na prevenção de doenças. 2016.57 f. Dissertação (Mestrado) - Curso de Ciências da Saúde, Universidade Fernando Pessoa, Porto, 2016.

SOUZA, A. W. S. de et al. Sistema Imunitário - Parte III O delicado equilíbrio do sistema imunológico entre os pólos de tolerância e autoimunidade. Revista Brasileira de Reumatologia, São Paulo, v. 50, n. 6, p.665-694, nov. 2010.

SOUZA, A. et al. Tolerância ou auto-imunidade? O delicado equilíbrio do Sistema Imunológico. Sinopse de Reumatologia, São Paulo, p.2-17, 2009.

SPERLING, M. A. Endocrinologia Pediátrica. 4. ed. Rio de Janeiro: Elsevier, 2015.

VELLOSA, J. C. R. et al. Alterações metabólicas e inflamatórias em condições de estresse oxidativo. Revista de Ciências Farmacêuticas Básica e Aplicada, Ponta Grossa, v. 34, n. 4, p.305-312, 2013.

VERRASATRO, T., LORENZI, T., WENDEL NETO, S. Hematologia e Hemoterapia: Fundamentos de Morfologia, Fisiologia, Patologia e Clínica. Rio de Janeiro: Ed. Atheneu, $1^{\circ}$ edição, 2010. 